\title{
THE PHYSICIAN'S PULSE WATCH
}

SIR JOHN FLOYER (1649-1734) may justifiably be credited with the invention of the first efficient instrument of precision to merit application in clinical practice. His own account of the development of a pulse watch for the accurate measurement of pulse rates in his patients has often been quoted, ${ }^{1-7}$ and the instrument is known to have been commercially available in $1707 . .^{8}$ But Gunn, ${ }^{3}$ writing in 1934 thought that no specimen had survived, and no example of such a pulse watch constructed in the last years of the seventeenth century has previously been illustrated in medical writings on the subject.

In opening his preface to the first volume of The Physician's Pulse Watch, published in 1707, Floyer described the evolution of the instrument:

I have for many years tried pulses by the minute in common watches and pendulum clocks, when I was among my patients. After some time I met with the common sea minute-glass, which I used for my cold bathing, and by that I made most of my experiments. But because that was not portable, I caused a pulse watch to be made which run 60 seconds, and I placed it in a box to be more carefully carried, and by this I now feel pulses. And since the watch does run unequally, rather too fast for my minute-glass, I thereby regulate it, and add 5 or 6 to the numbers told by the watch. I also made a half minute-glass, whose case turns like a dark lanthorn and that was portable and useful in feeling of my patients' pulses, but that differed 4 beats from the minute glass, which I kept at home as my standard.

It had been possible to 'try pulses by the minute in common watches' since 1670 when the royal clockmaker, Daniel Quare, added a concentric minute hand to his watches. ${ }^{\circ}$ The addition of a seconds hand to a watch was made in order to fulfil Floyer's medical requirements. 'With the exception of a watch made by John Fitter, English, in 1665, there was no application of a second hand on a watch until Floyer invented his pulse-watch'. ${ }^{10}$ There is no doubt about the identity of Samuel Watson as the maker of Floyer's pulse watch. ${ }^{8}$

Samuel Watson was one of the masters of horology of the late seventeenth century, whose surviving works entitle him to rank among the great makers of his day. ${ }^{11}$ He was born in Coventry, in about 1635 and became Sheriff of his native city in

${ }^{1} \mathrm{~S}$. Weir Mitchell, 'The early history of instrumental precision in medicine', Trans. Congr. Amer. Phycns Surg., 1891, 2, 177-78.

'Logan Clendenning, 'The history of certain medical instruments', Ann. intern. Med., 1930, 4, 176-77. 298. A. Gunn, 'Sir John Floyer (1649-1734), British Masters of Medicine', Med. Press, 1934, 188,

-D. Evan Bedford, 'The ancient art of feeling the pulse', Brit. Heart J., 1951, 13, 435.

- Lilian Lindsay, 'Sir John Floyer (1649-1734)', Proc. roy. Soc. Med., 1951, 44, 47.

- Gary L. Townsend, 'Sir John Floyer (1649-1734), and his study of pulse and respiration', $J$. Hist. Med., 1967, 22, 297-98.

'D. D. Gibbs, 'Sir John Floyer, M.D. (1649-1734)', Brit. med. J., 1969, i, 242-45.

- Sir John Floyer, The Physician's Pulse Watch; or, an essay to explain the old art of feeling the pulse and to improve it by the help of a pulse-watch, Vol. I, London, S. Smith and B. Walford, 1707.

An advertisement inserted with the instruction 'place this after the contents' records that 'the pulse-watch, here treated of, is made and sold by Mr. Samuel Watson, watch-maker in Long Acre, by Sir John Floyer's direction.'

- James Kendall, A History of Watches and other Time Keepers, London, 1892, p. 117.

10 F. J. Britten, Old Clocks and Watches and their Makers, 3rd ed., London, Batsford, 1911, p. 225.

11 H. Alan Lloyd, 'Samuel Watson', Antiquarian Horology, 1954, i, 60-61. 
1686. ${ }^{12} \mathrm{~A}$ few years later he moved to London and in 1692 the rate books of St. Martin-in-the-Fields record him as living in Long Acre. ${ }^{13}$ In the same year the records of the Clockmaker's Company indicate that he was admitted as a brother, a necessity if he were to work and trade in London.

Samuel Watson was Mathematician-in-Ordinary to King Charles II, and his great masterpiece was made upon the King's command in 1683.14 This four-dialled astronomical clock, now in the Library of Windsor Castle, was described by a contemporary as a 'rare celestial orbitery'. ${ }^{15}$ It showed a remarkable range of celestial movements, including the hour, day, month, year, rising and setting of the sun, phases of the moon, the position of the moon, the position of the sun and moon in the ecliptic and the motions of the planets through the zodiacal band. Sir John Floyer could hardly have been more fortunate in obtaining the services of a clockmaker of such resource and ingenuity, to meet his requirements for a pulse watch.

Samuel Watson began his work in Coventry, and it was presumably at this time that Floyer, who practised as a physician throughout his working life in Lichfield, about twenty-five miles away, first discussed the project. An example of a Watson pulse watch, previously in the possession of Mr. H. Alan Lloyd and subsequently acquired by the late Mr. T. P. Camerer Cuss, has been illustrated in the horological literature. ${ }^{16,17} \mathrm{I}$ am indebted to the late Mr. Camerer Cuss and his son Mr. Terence Cuss for the following description of the watch:

Pulse Watch, circa 1695, Silver plain pair-cases; square hinge; stirrup bow pivoted to flat pendant knob; silver champlevé dial with seconds dial; steel tulip hour hand and poker minute; normal verge movement with seconds hand taken off the fourth wheel. The stop lever for the seconds hand is exposed when the ou ter case is removed. The design on the table of the cock springs from a cherub's head; streamers to table. The edge of the cock foot follows the contour of the plate. The stop lever can be seen on the right-hand side of the movement which is signed 'S. Watson, London.'

There were two special features incorporated into the watch, a seconds hand and a pushpiece to stop the watch. In this prototype of stop watches the pushpiece stopped the whole movement. But both these devices were horological innovations and 'were the first step on the road to split-second chronometers of today'.

It is not known how many pulse watches Watson constructed, nor to what extent other clock- and watch-makers followed his example. That there were modifications is certain. Floyer, in 1724, seventeen years after publishing his first observations with the pulse watch, pointed out that a suitable watch 'may easily be made by making the minute-finger larger and to run round the plate'. ${ }^{18}$ In 1710 he recorded his gratitude to

\footnotetext{
12 Victoria County History, Warwickshire, Vol. 2, ed. William Page, London, Constable, 1908, p. 242.

Reference is made to William Watson, clockmaker, Sheriff of Coventry, but Thomas Sharp in his List of Mayors, Bailiffs, and Sheriffs, of Coventry to 1830, quotes Samuel Watson as Sheriff for 1686.

${ }_{13}$ H. Alan Lloyd, Some Outstanding Clocks over Seven Hundred Years, 1250-1950, London, Leonard Hill, 1958, p. 89.

is H. Alan Lloyd, 'The work of Samuel Watson of Coventry and London (ca. 1635-ca. 1710)', Horological Journal, 1942, 84, 298-311.

${ }_{15}$ John Smith, Horological Disquisitions Concerning the Nature of Time, London, 1694, p. 17.

16 H. Alan Lloyd, 'Samuel Watson', Antiquarian Horology, 1954, 6. 61.

17 T. P. C. Cuss, Book of Watches, London, Country Life, 1967, p. 34.

${ }^{18}$ Sir John Floyer, Medicina Gerocomica, London, 1724, Preface, p. xxi.
} 


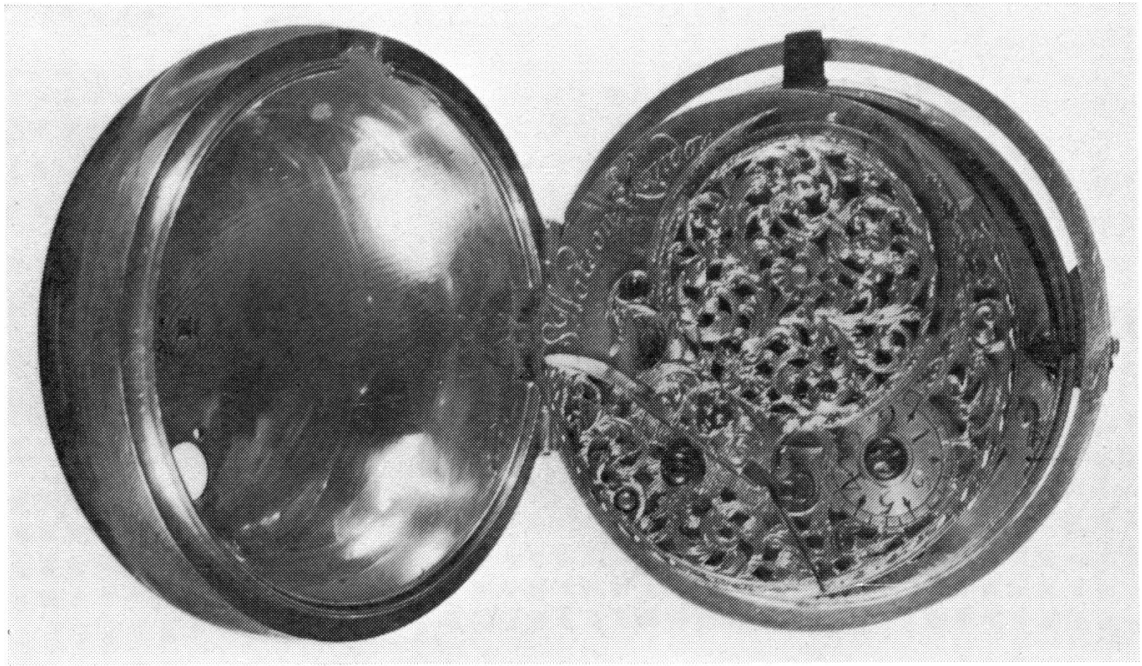

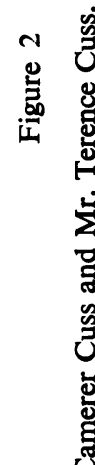

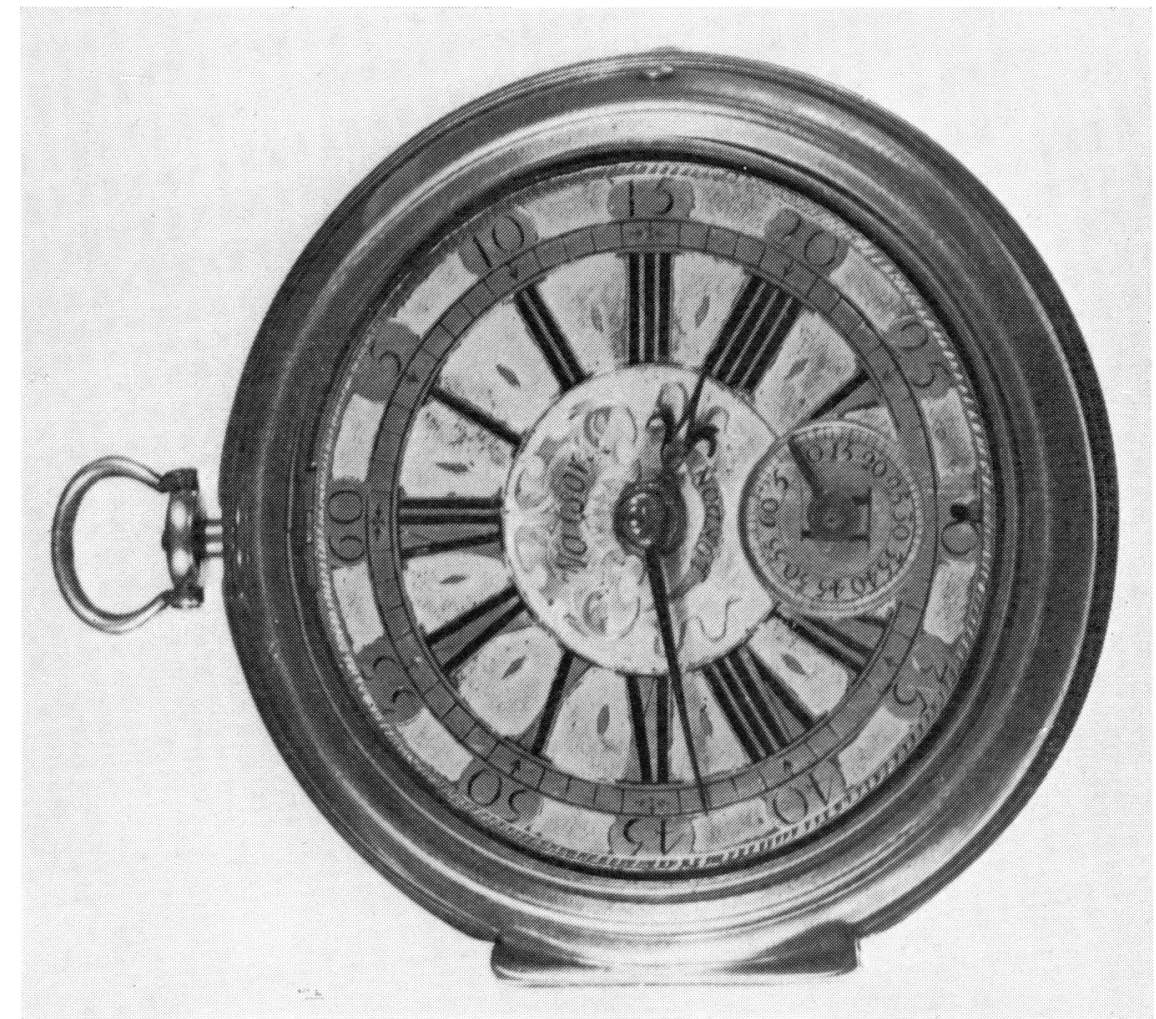



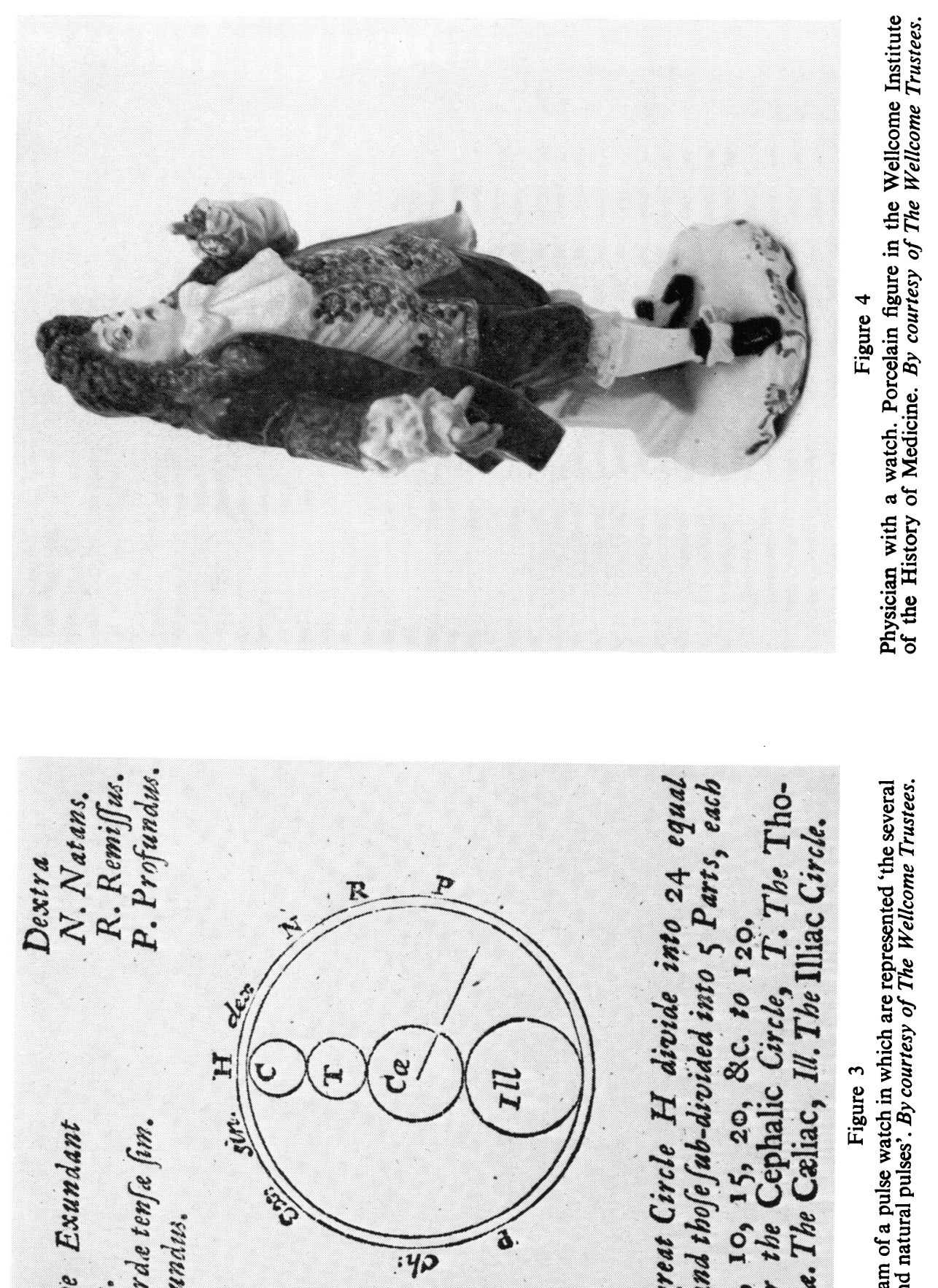

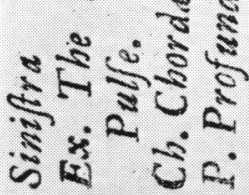

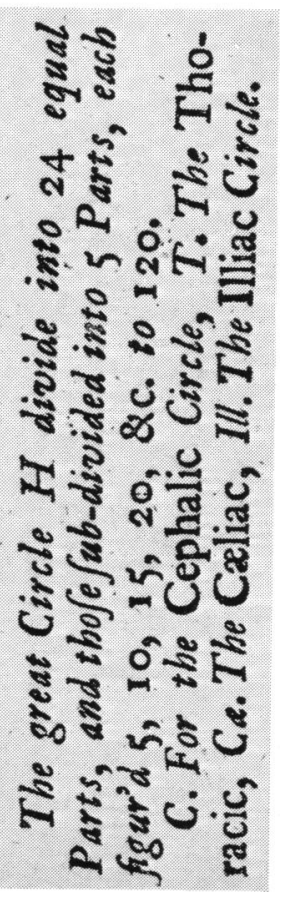

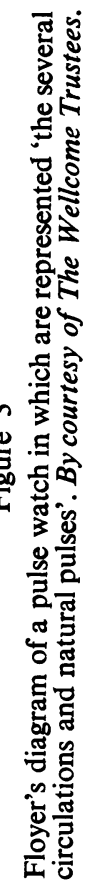




\section{News, Notes and Queries}

an unknown benefactor who sent him a pulse watch of improved accuracy. "which runs but one second short of my minute-glass'. ${ }^{19}$ In the second volume of the Physician's Pulse Watch (1710) he also 'annexed the figure of a pulse-watch, representing the several circulations and natural pulses' (fig. 3). ${ }^{20}$ By this time he had become deeply immersed in Chinese pulse lore as expounded in Cleyer's Specimen Medicinae Sinicae. ${ }^{21} \mathrm{He}$ does not divulge how readings were made from this watch face.

The illustration (fig. 3) epitomizes the conflicting forces and influences so evident in Floyer's writings. On the one hand, he developed the first efficient device for 'bedside' clinical measurement and he tabulated the vital signs of pulse and respiration rates, made under different conditions, in a form which found no equal for 150 years. On the other hand, in searching for the relevance of his scientific clinical measurements he was confined within the framework of existing philosophies. It is tempting to think that the limitations which he recognized in the Galenical system and his need to look outside accepted ideas in the West, were responsible for his credulous acceptance of much of the infinitely more complex Chinese doctrines on the pulse.

In the seventeenth century a watch became part of the display of the physician, but the purpose for which Floyer asked Watson to construct the original pulse watch was largely forgotten. There were exceptions, of which the recommendations of Heberden serve as an example.

It is to be wished . . . that physicians in their doctrine of pulses, and descriptions of cases, had attended more to such circumstance of the pulse, in which they would neither mistake, nor be misunderstood. Fortunately there is one of this sort, which not only on this account, but likewise for its importance, deserves attention. What I mean is the frequency or quickness of the pulse ... it is capable of being numbered and consequently of being most perfectly described and communicated to others. ${ }^{22}$

The more usual application of a pulse watch a century or so after its invention is suggested in a book giving Advice and Maxims for Young Students and Practitioners of Medicine, with Remarks on the Pulse. 'It is a pompous practice too much in fashion on all occasions, to time the pulse by a fine gold watch, which, perhaps, may be thought to give consequence, like a bag wig and gold-headed cane'23 (fig. 4).

The watch was reinstated as a means of accurate timing of pulse and respiration rates, under the influence of the Dublin school in the mid-nineteenth century. Graves gave his view on the subject in a lecture on the pulse: 'I do not know, gentlemen, any point on which accurate observations are more wanting than on the proportion between the pulse and the respiration in various states of the system, and in various

10 Sir John Floyer, The Pulse Watch, London, J. Nicholson, W. Taylor and H. Clements, 1710, Vol. 2, p. 327.

20 Ibid., p. 328.

11 Andreas Cleyer, Specimen Medicinae Cinicae, Frankfurt, J. P. Zubrodt, 1682. Floyer's copy, which he received as a gift from the Hon. Charles Hatton, was included in his bequest to the Library of the Queen's College, Oxford. He records that he was infinitely obliged for the present, "which I have read very often before I could understand it.' 18.

22 William Heberden, Commentaries on the History and Cure of Diseases, 2nd. ed., London, 1803. Appendix 3. Remarks on the pulse, read at the College of Physicians, July 7th, 1768.

Daniel Johnson, Advice and Maxims for Young Students and Practitioners of Medicine, with Remarks on the Pulse, London, 1820, p. 28. 


\section{News, Notes and Queries}

diseases'. ${ }^{24}$ The figure of the Victorian doctor, watch in hand, became familiar, and leaves an impression that he shared in Floyer's earnest attempts to use pulse timing so that 'we may know the natural pulse and the excesses and defects from this in disease'. ${ }^{25}$

24 Robert J. Graves, Clinical Lectures on the Practice of Medicine, reprinted from the second edition, London, New Sydenham Society, 1864. Lecture IV: The Pulse.

${ }^{26}$ Sir John Floyer, The Physician's Pulse-Watch, Vol. 1, London, S. Smith and B. Walford, 1707, p. 13.

\section{ACKNOWLEDGEMENTS}

The late Mr. T. P. Camerer Cuss and Mr. Terence Cuss showed me a Watson pulse-watch and introduced me to the horological details. Information kindly supplied by Mr. F. A. B. Ward and Mr. H. Alan Lloyd led me to the pulse-watch. It is a pleasure to acknowledge the assistance of the staff of the Wellcome Institute of the History of Medicine.

D. D. GIBBS

\section{PROPHYLACTIC ENUCLEATION IN SYMPATHETIC OPHTHALMITIS THE EVOLUTION OF AN HEROIC FORM OF TREATMENT}

To ENUCLEATE an eye as a prophylactic measure against sympathetic ophthalmitis always requires an act of courage. To have initiated such treatment originally must have been heroic, especially as it was known that the second eye might eventually be the more seriously affected. Yet the development of this form of treatment in the nineteenth century was a slow and highly responsible process, based on speculation, observation and careful thought.

The germ of this idea may be found in the writings of James Wardrop (1782-1869) (fig. 1), a Scottish surgeon of character and insight, fond of field sports and with considerable knowledge of horses. Indeed he wrote an article entitled An Essay on Diseases of the Eye of the Horse and their Treatment. Between 1808 and 1818 Wardrop's Essays on the Morbid Anatomy of the Human Eye was published in Edinburgh. In the chapter 'Of the Sympathies of the Eye' dealing with bilateral diseases of the eye in general, the following passage is found:

... there is a disease, frequent in the eye of the horse, having the appearance of a specific inflammation, which usually first affects one eye and then the other, almost always sooner or later destroying vision. It is known among some Farriers, that, if the eye first affected with this disease suppurates and sinks into the orbit, the disease does not attack the other eye, or subsides if it has commenced in it. Thus they have adopted a practice of destroying altogether the diseased eye, in order to save the other which is rudely done by putting lime between the eyelids, or thrusting a nail into the cavity of the eyeball, so as to excite violent inflammation and suppuration. I have frequently succeeded in saving one eye of the horse by adopting this practice; but I destroyed the eye simply by making an incision in the cornea, and discharging through it the lens and vitreous humour. In some diseases of the human eye, where the disease makes a similar progress, first affecting one eye and then the other with complete blindness, the practice so successful in animals might, by judicious discrimination, be beneficially adopted. ${ }^{1}$

Yet the concept of sympathetic ophthalmitis as a separate disease that affects the second eye some time after an injury to the first was not clearly defined until William Mackenzie of Glasgow described it in the later editions of his famous textbook 